\title{
Glycaemic Control in Pancreatectomized Dogs with a Wearable Artificial Endocrine Pancreas
}

\author{
M. Shichiri, R. Kawamori, Y.Goriya, Y. Yamasaki, M. Nomura, N.Hakui, and H. Abe \\ First Department of Medicine, Osaka University Medical School, Osaka, Japan
}

\begin{abstract}
Summary. A needle-type glucose sensor has been developed using a platinum electrode covered with immobilized glucose oxidase. Experiments with albumin-saline solution in vitro showed that at $5.5 \mathrm{mmol} / 1$ glucose concentration the output current generated was $1.2 \pm 0.4 \mathrm{nA}$ (mean $\pm \mathrm{SD}$ ). The current increased as a linear function of glucose concentration over the range $(0-27.7 \mathrm{mmol} / 1)$. The response time to reach $90 \%$ of the final plateau value was $16.2 \pm 6.2 \mathrm{~s}$. The signal-to-noise ratio of the sensor was $15.8 \pm 2.6$ decibels. The temperature coefficient in output was $2.3 \pm 1.0 \% /{ }^{\circ} \mathrm{C}$. The current output was not affected significantly by changes in oxygen tension of the solution in the range $25-150 \mathrm{mmHg}$.

In vivo, the output current of sensors inserted into the subcutaneous tissues of dogs was directly related to blood glucose concentrations after oral glucose or meals. Daily checking of the sensors maintained in subcutaneous tissues in five dogs
\end{abstract}

showed that the sensitivity decreased gradually to $87.2 \pm 7.6 \%$ at $72 \mathrm{~h}$, and dropped significantly to $57.4 \pm 7.0 \%$ of the initial output by $96 \mathrm{~h}$.

A wearable artificial endocrine pancreas $(18.0 \times 17.7 \times$ $7.9 \mathrm{~cm}, 700 \mathrm{~g}$ ) was developed, consisting of a needle-type glucose sensor, a microcomputer system and a pump driving mechanism. Three pancreatectomized dogs were fitted with the system by inserting the sensor into subcutaneous tissue. By renewing the sensor every fourth day, the device could maintain the daily glucose variations in diabetic dogs within the range $5-9.5 \mathrm{mmol} / 1$ for 7 days.

Key words: Artificial endocrine pancreas, needle-type glucose sensor, closed-loop insulin infusion system, blood glucose control.
The bedside-type of artificial endocrine pancreas [1-7], the closed-loop control system, used in the treatment of diabetic patients has revealed that insulin delivery in response to measured blood glucose concentrations on a minute-by-minute basis can normalize glycaemia in diabetic patients following various stimuli [3-6]. However, the problems associated with long-term venous access and the size of the artificial endocrine pancreas have demonstrated that this system has a limited applicability in clinical practice [7]. The miniaturization of a glucose monitoring system is an essential requirement for its clinical application. We have succeeded in miniaturizing the glucose monitoring system into a needle-type device which preserves the characteristics applicable in a wearable closed-loop glucose regulatory system. Glucose monitoring systems measuring hydrogen peroxide are widely used in the bedside-type of artificial endocrine pancreas $[4,5]$. In developing this principle, we have used a sensor consisting of a platinum anode and a silver cathode. The electrodes loaded with $0.6 \mathrm{~V}$ polarographic voltage measure hydrogen peroxide, which is produced by the enzymatic reaction of glucose at the site of the immobilized glucose oxidase membrane. For developing the wearable closed-loop system, a sensor, a microcomputer system to calculate the insulin infusion rate and a syringe-driving system are packed into a small box. The glycaemic control of pancreatectomized dogs with the system was attempted in order to evaluate the feasibility of this device for possible clinical application.

\section{Materials and Methods}

\section{Needle-type Glucose Sensor}

The structure of the sensor is shown in Figure 1. The tip of a Pt wire (diameter $0.2 \mathrm{~mm}$, length $4 \mathrm{~cm}$ ) was melted in an $\mathrm{O}_{2}$ flame to form a small bulb (0.3-0.7 mm diameter) and the wire was sealed into a soft glass tube. After polishing the Pt bulb (anode) with fine sandpaper, a stainless steel silver-plated tube was placed in contact to serve as the cathode. The electrode tip was dipped into a suspension of glucose oxidase $(1.08 \mathrm{mmol} / \mathrm{l}, 17300 \mathrm{U} / \mathrm{g}$, type II, Sigma Chemicals, Saint 


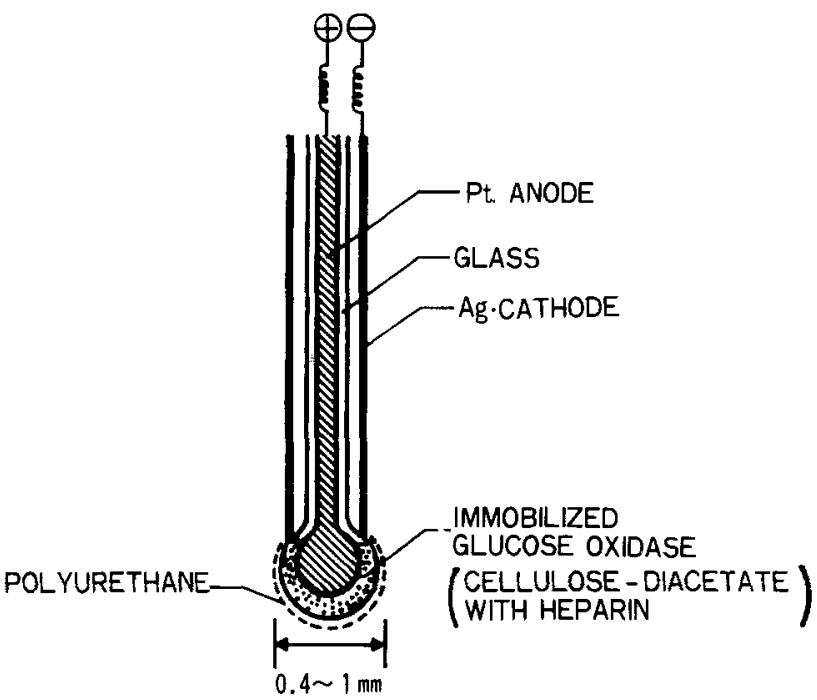

Fig. 1. Structure of a needle-type ghucose sensor

Louis, USA) and heparin $(0.6 \mathrm{mmol} / 1,170 \mathrm{U} / \mathrm{mg}$, Novo, Copenhagen, Denmark) in acetone/ethanol (1:1) containing cellulose diacetate $(2.5 \%)$. After drying in air, the tip was dipped into polyurethane $(10 \%)$ dissolved in dimethylformamide/tetrahydrofuran (1:9) and again air-dried. The sensor thus prepared was $2 \mathrm{~cm}$ in length and $0.4-1 \mathrm{~mm}$ in diameter.

\section{Determination of Sensor Characteristics}

The characteristics of the sensor were tested in $0.9 \% \mathrm{NaCl}$ solution containing $7 \%$ bovine albumin (Fraction V, Miles, Elkhart, USA) with varying glucose concentrations equilibrated in $5 \% \mathrm{O}_{2}$ at $37^{\circ} \mathrm{C}$ in a temperature- and flow rate-controllable chamber. The drift of the baseline, noise and residual current of the sensor were expressed as a percentage change of the sensitivity in $5.5 \mathrm{mmol} / 1$ glucose solution. The dose-response pattern and rapidity of the sensor current to alteration in glucose concentration and the temperature coefficient were measured using the same chamber, either by infusing the solution with $(0-27.7) \mathrm{mmol} / 1$ glucose at $37^{\circ} \mathrm{C}$ or by changing the temperature of the solution from $33{ }^{\circ} \mathrm{C}$ to $42^{\circ} \mathrm{C}$. The current dependency on $\mathrm{O}_{2}$ tension was checked by admitting varying $\mathrm{O}_{2} / \mathrm{N}_{2}$ gas mixtures to the solution and monitoring the $\mathrm{O}_{2}$ tension $(0-150 \mathrm{mmHg})$ with an $\mathrm{O}_{2}$ sensor. Changes in current were expressed as a percentage of the current output obtained in solution with $5 \% \quad \mathrm{O}_{2}(38 \mathrm{mmHg})$ and $5.5 \mathrm{mmol} / 1$ glucose at $37^{\circ} \mathrm{C}$.

The life expectancy of the glucose sensor was examined in the chamber by continuous recirculation of a solution containing glucose $(5.5 \mathrm{mmol} / \mathrm{l})$. Each sensor was equilibrated in this solution for $2 \mathrm{~h}$ and output currents were recorded continuously for 7 days without altering the sensor's sensitivity.

\section{Monitoring of Glucose Concentration with a Sensor in Vivo}

Following general anaesthesia with sodium pentobarbital, a glucose sensor was inserted by means of an indwelling needle (gauge No.16) into a jugular vein, abdominal muscle, or SC tissue in the jugular region of five normal dogs (weight $10-11 \mathrm{~kg}$ ). Each sensor was equilibrated in $0.9 \% \mathrm{NaCl}$ solution containing $7 \%$ albumin and was perfused with $5 \% \mathrm{O}_{2}$ at $37^{\circ} \mathrm{C}$ for at least $2 \mathrm{~h}$ prior to calibration with a standard glucose solution $(11 \mathrm{mmol} / \mathrm{l})$. The dogs were then subjected to either oral glucose $(20 \mathrm{~g})$, or an IV glucose pulse injection $(0.44 \mathrm{~g} /$ $\mathrm{kg}$ ) followed by insulin ( $4 \mathrm{U} / \mathrm{kg}$, Actrapid, Novo, Copenhagen, Denmark). The glucose concentrations obtained by the needle-type glu- cose sensor were compared with those measured by the bedside-type of artificial endocrine pancreas [2-4]. Daily variations of the sensitivity of the sensors maintained in SC tissue were investigated in five normal dogs by examining the current outputs after removing the sensors from the sites of insertion.

To examine the effect of changes in tissue $\mathrm{O}_{2}$ tension on the output of sensors inserted into $\mathrm{SC}$ tissue, the following experiments were conducted: needle-type $\mathrm{O}_{2}$ electrodes and glucose sensors were inserted into the SC tissue of five normal dogs and blood glucose levels were monitored continuously by the bedside-type of artificial endocrine pancreas. Inhalations of $100 \% \mathrm{~N}_{2}$ and $95 \% \mathrm{O}_{2} / 5 \% \mathrm{CO}_{2}$ were performed repeatedly and the relationship between tissue oxygen tension and the output of the glucose sensors was examined.

\section{The Wearable Artificial Endocrine Pancreas}

The total system was packed into a small box $(18.0 \times 17.7 \times 7.9 \mathrm{~cm}$, weight $700 \mathrm{~g}$ ), and consisted of a current-voltage converting amplifier, an 8-bit $\mathrm{AD}$ converter, an 8-bit CPU, a 4K PROM containing insulin infusion algorithms, a $1 \mathrm{~K}$ RAM for storing measured glucose data, a crystal-display mechanism, a pump driving mechanism, a $5-\mathrm{ml}$ syringe for insulin infusion, and a battery supply. These chips were mounted on two boards $(17 \times 14 \mathrm{~cm})$. The insulin infusion rate was determined on the basis of proportional and derivative actions to glucose concentration according to the following equation. Detailed explanations of these algorithms have been published elsewhere $[2-4,12]$.

Insulin infusion rate $\left(\mathrm{mU} \cdot \mathrm{min}^{-1} \cdot \mathrm{kg}^{-1}\right)=\mathrm{Kp} \mathrm{BG}(\mathrm{t})+\mathrm{Kd} \Delta \mathrm{BG}(\mathrm{t})$ $+\mathrm{Kc}$ where $\mathrm{BG}(\mathrm{t})$ and $\Delta \mathrm{BG}(\mathrm{t})$ are glucose concentration (mmol/1) and its derivative change ( $\left.\mathrm{mmol} \cdot \mathrm{1}^{-1} \cdot \mathrm{min}^{-1}\right)$ at time $\mathrm{t}$, respectively; $\mathrm{Kp}$ and $\mathrm{Kd}$ are coefficients for the proportional and derivative action, respectively and $\mathrm{Kc}$ is the constant for basal insulin supplementation.

\section{Attempted Glycaemic Control in Pancreatectomized Dogs}

After pancreatectomy, three dogs (weight $8.1-11.0 \mathrm{~kg}$ ) were injected daily with insulin (2U/kg, Actrapid and Semilente, Novo, Copenhagen, Denmark). The dogs, all with fasting blood glucose levels $>17 \mathrm{mmol} / 1$, were fitted with a wearable artificial endocrine pancreas $48 \mathrm{~h}$ after withdrawal of insulin. At this time, all three dogs had ketonaemia and plasma free insulin concentrations were not detectable by radioimmunoassay [8]. Following calibration, a sensor was inserted into the SC tissue of the back of the dog by means of an indwelling needle and fixed to the body with adhesive bandages. A mixed meal of $40 \mathrm{Cal} / \mathrm{kg}$ ( $40 \%$ carbohydrate, $30 \%$ protein, $30 \%$ fat) with digestive enzymes was given at $10.00 \mathrm{~h}$ and $18.00 \mathrm{~h}$. Parameters for insulin infusion algorithms were selected as follows: $\mathrm{Kp}=0.151$, $\mathrm{Kd}=1.458, \mathrm{Kc}=-0.45$. The infusate contained $2.5 \mathrm{U} / \mathrm{ml}$ of insulin with $5 \%$ added gelatine. The catheters were inserted; one in the antecubital vein for insulin infusion, the other into a femoral vein for blood sampling of plasma insulin [8]. During the 7-day control period, after 3-days of continuous use, the needle-type glucose sensors were removed from the insertion sites and recalibrated. When the sensitivity of the sensors showed $<85 \%$ of the initial level, they were replaced by new ones.

The results are expressed as mean $\pm \mathrm{SD}$, and the Student's t-test for paired groups is used for statistical analysis.

\section{Results}

\section{Characteristics of the Sensors}

The characteristics of the sensor are shown in Table 1 and the effect of $\mathrm{O}_{2}$ tension on the output current is displayed in Figure 2. Sensors outputs increased gradually 
Table 1. Characteristics of the needle-type glucose sensor in vitro

\begin{tabular}{lc}
\hline Test & Performance \\
\hline Residual current $(\%)$ & $1.3 \pm 0.6$ \\
Baseline drift $(\% / 24 \mathrm{~h})$ & $0.8 \pm 1.3$ \\
Noise range $(\%)$ & $0.3 \pm 0.4$ \\
Output current generated to $5.5 \mathrm{mmol} / 1 \quad(\mathrm{nA})$ & $1.2 \pm 0.4$ \\
Signal-to-noise ratio (decibels) & $15.8 \pm 2.6$ \\
Range of glucose concentrations producing a linear & $0-27.7$ \\
dose-response pattern (mmol/1) & $16.2 \pm 6.2$ \\
T90\% response time (s) & $2.3 \pm 1.0$ \\
Temperature coefficient $\left(\% /{ }^{\circ} \mathrm{C}\right)$ &
\end{tabular}

Results are shown as mean $\pm S D$ for 15 sensors

$(0.15 \% / \mathrm{mmHg})$ with elevation of $\mathrm{O}_{2}$ tension in the range $25-150 \mathrm{mmHg}$, but this difference was not statistically significant whereas at $15 \mathrm{~mm} \mathrm{Hg}$ a significant decrease was observed $(78.0 \pm 17.2 \%, p<0.01)$.

The life expectancy of 15 glucose sensors in the albumin-saline solution was demonstrated by a gradual decrease in output over 3 days; values of $97.2 \pm 1.8 \%$, $95.2 \pm 3.0 \%$, and $92.6 \pm 3.4 \%$ were recorded after 24,48 and $72 \mathrm{~h}$, respectively. These differences were not significant statistically, but reduced significantly $(p<$ 0.01 ) to $86.4 \pm 4.0 \%$ and $76.2 \pm 6.9 \%$ after 96 and $168 \mathrm{~h}$, respectively, when compared with the initial $(100 \%)$ output after $2 \mathrm{~h}$ pre-incubation.

\section{Monitoring in Vivo}

Outputs of sensors kept in the jugular vein (Y) related to the results of IV glucose monitoring by the bedside-type of artificial endocrine pancreas system $(\mathrm{X})(\mathrm{Y}=0.98 \mathrm{X}$ $+0.11, r=0.998, p<0.01)$. Intramuscular or SC measurement showed lower peaks $(82.8 \pm 4.8 \%, p<0.01$ in muscle, and $64.2 \pm 8.9 \%, p<0.01$ in SC tissue) and a delayed response (5-10 $\mathrm{min}$ in muscle and 5-15 min in SC tissue) after IV glucose pulse loads, compared with the mean peak value of IV monitoring in the five dogs. However, after oral glucose loads, SC glucose concentrations were $15 \%$ lower and showed delayed responses of 2-5 min compared with IV glucose monitoring. Nevertheless, a significant relationship existed between the glucose concentrations obtained by the needle-type sensors in SC tissue and the blood glucose concentrations determined by bedside-type monitoring systems (Fig. 3).

Daily checking of the sensors kept in SC tissue in five dogs showed that the sensitivity decreased gradually to $93.6 \pm 6.0 \%$ at $24 \mathrm{~h}, 90.4 \pm 5.4 \%$ at $48 \mathrm{~h}$, and $87.2 \pm 7.6 \%$ at $72 \mathrm{~h}$, but by $96 \mathrm{~h}$ it was only $57.4 \pm 7.0 \%$ of the initial output $(p<0.01)$.

In five dogs, when the tissue $\mathrm{O}_{2}$ tension was varied from $27-72 \mathrm{mmHg}$ by inhalation of $\mathrm{N}_{2}$ or $\mathrm{O}_{2}$, the output current of the glucose sensor was not significantly affected. Figure 4 shows the results in a representative dog.

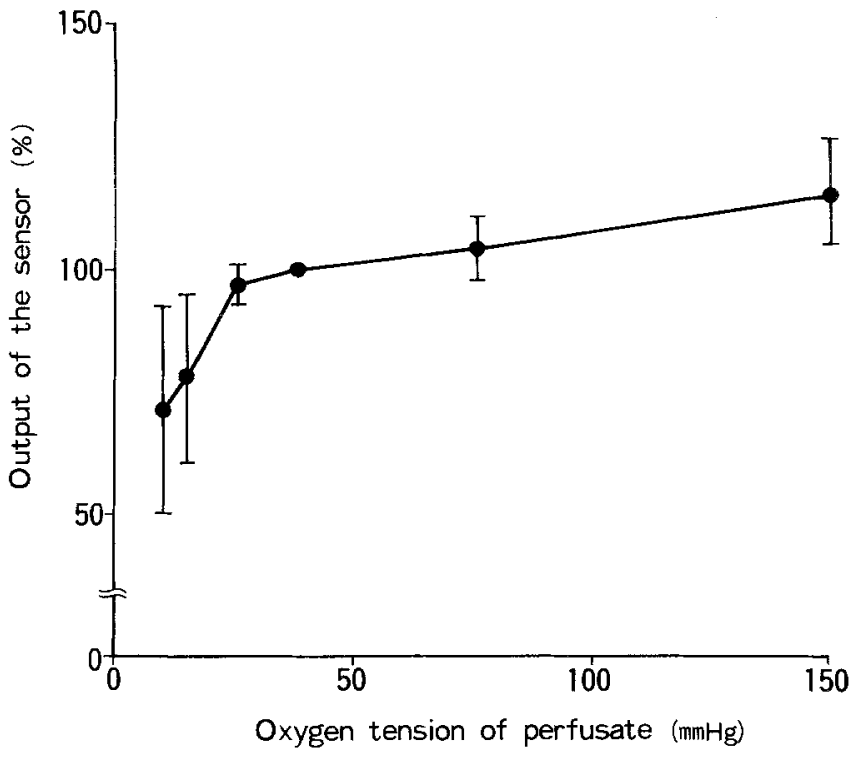

Fig. 2. Dependency of output current of the needle-type glucose sensor on oxygen tension of buffer solution containing $0.9 \% \mathrm{NaCl}, 7 \%$ bovine albumin and $5.5 \mathrm{mmol} / 1$ glucose. The output obtained at an oxygen tension of $38 \mathrm{mmHg}$ was standardized as $100 \%$. Results expressed as mean $\pm \mathrm{SD}, n=15$

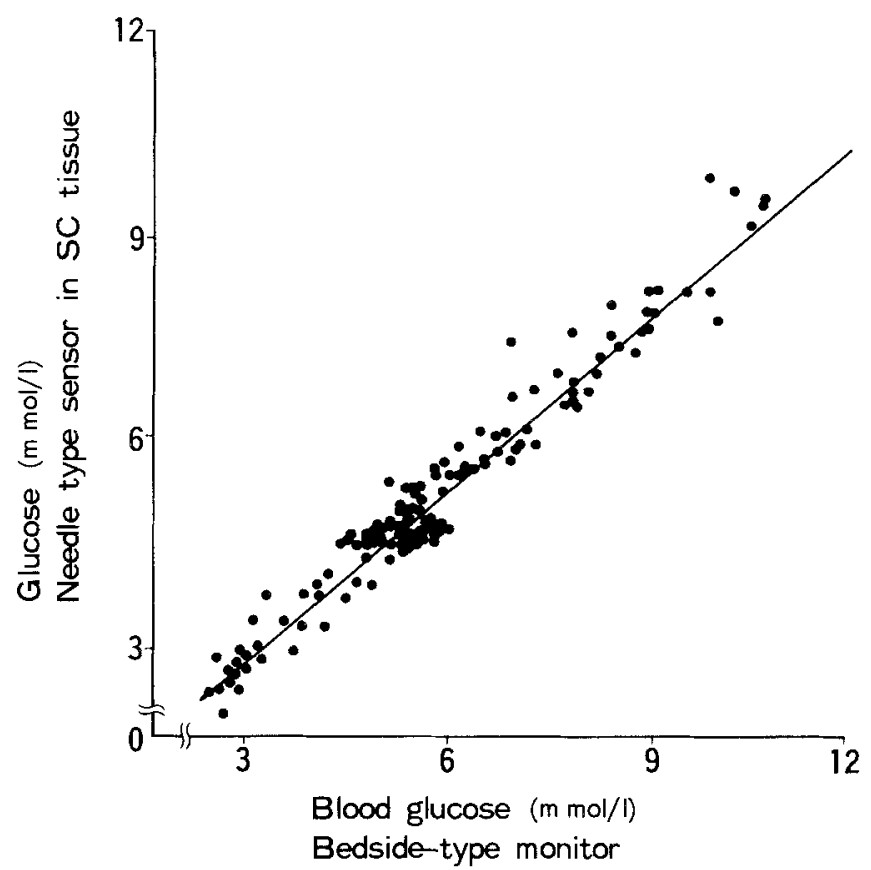

Fig. 3. The relationship between glucose concentration determined by the needle-type glucose sensor inserted into SC tissue and blood glucose concentration determined by the bedside-type of artificial endocrine pancreas system. ( $\mathrm{Y}=0.85 \mathrm{X}+0.18, r=0.956, p=<0.01$, $n=144$ )

\section{Treatment of Pancreatectomized Dogs with the Wearable Artificial Endocrine Pancreas}

Figure 5 shows the circadian profiles of glycaemic control and plasma insulin concentrations in a representative pancreatectomized dog at the time of pre-control, 


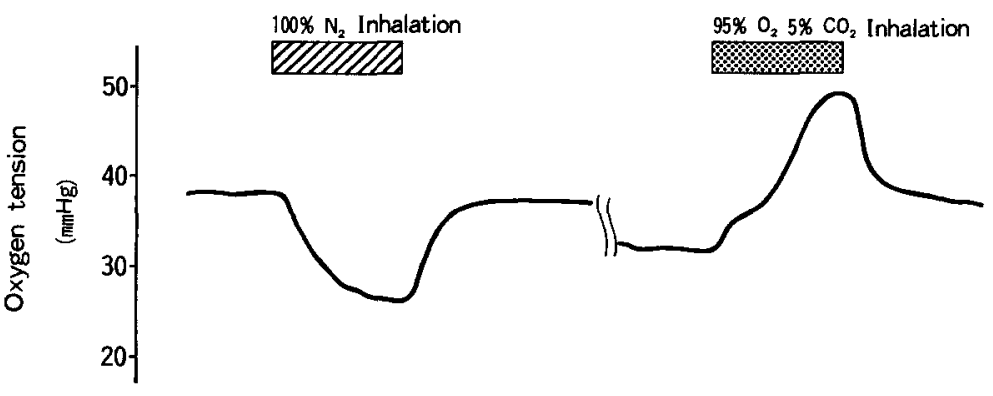

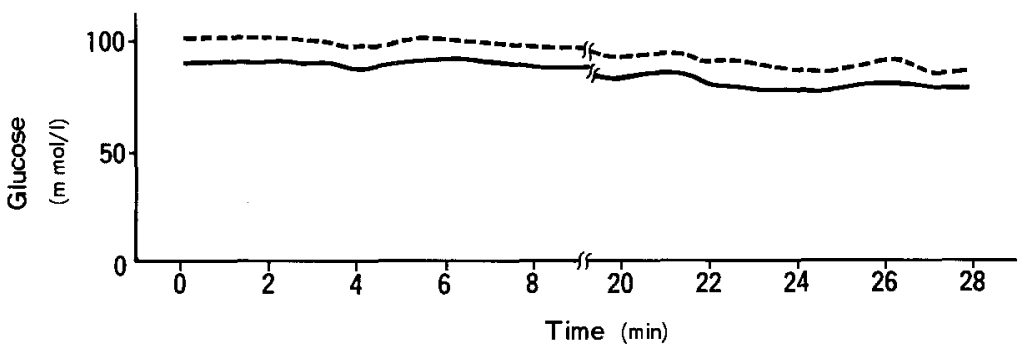
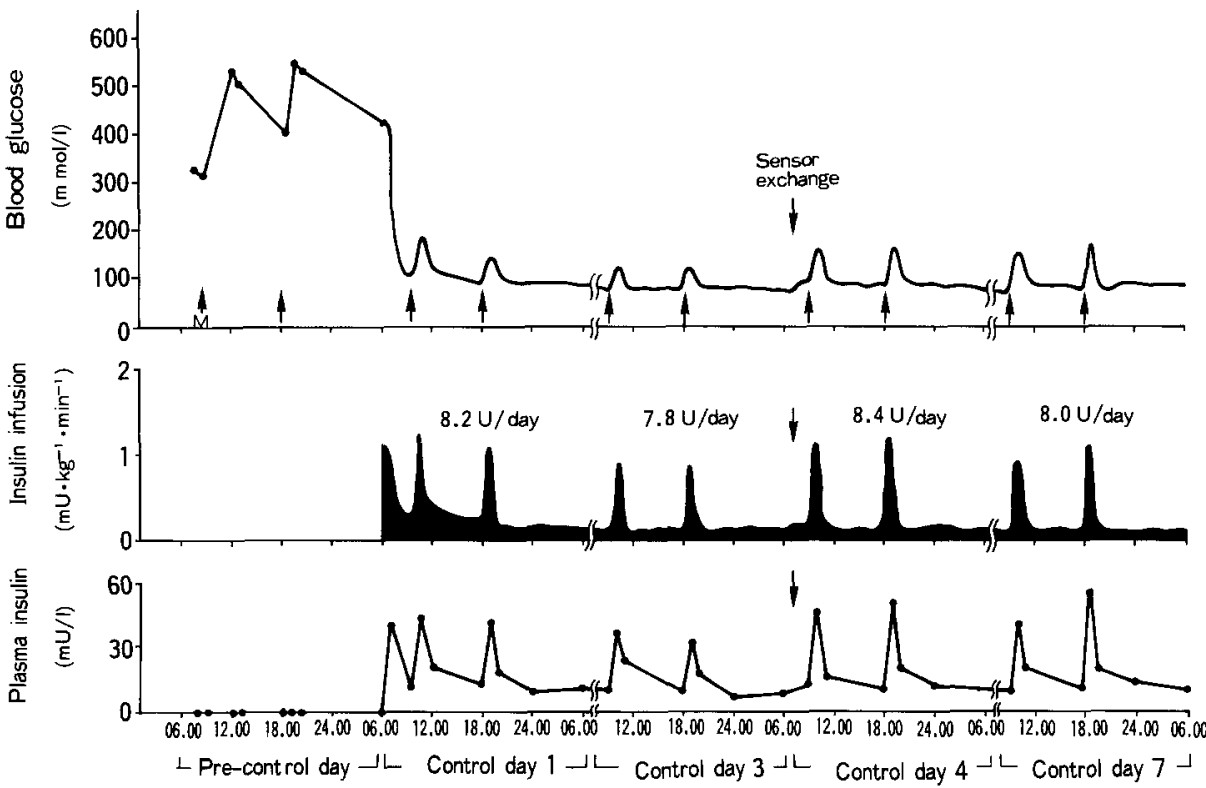

Fig. 4. Upper panel: The effect of changes in tissue oxygen tension on the output current of the needle-type glucose sensor inserted into SC tissue. Lower panel: The monitoring records are shown of glucose concentrations by a needle-type sensor ( - ) and a bedside-type of artificial endocrine pancreas system (---)
Fig.5. Circadian profiles of glucose concentration measured by the needle-type glucose sensor and plasma insulin concentration in a pancreatectomized dog controlled with the wearable artificial endocrine pancreas. Mixed meal of $40 \mathrm{Cal} / \mathrm{kg}(\uparrow)$ were given to the dog at 10.00 and $18.00 \mathrm{~h}$. Glycaemia on the precontrol day and days 1, 3, 4 and 7 are shown. The sensor was replaced by a new one at $06.00 \mathrm{~h}$ on control day 4 . Continuous insulin infusion rates and daily plasma insulin levels are also depicted and on control days $1,3,4,7$ with a wearable artificial endocrine pancreas. A summary of the results in three pancreatectomized dogs is shown in Table 2. During treatment all three glucoregulatory indices were reduced to within the range of values seen in normal dogs.

\section{Discussion}

It has been accepted that the major obstacle in developing a wearable or implantable artificial endocrine pancreas is the difficulty in preparing an implantable glucose sensor. Therefore, miniaturization of the glucose sensor, preserving its characteristics of accuracy, stability and specificity to glucose, without blood loss during monitoring are essential. As a possible implantable sen- sor, the enzyme electrode system is useful because of its specificity. Two methods are now available to measure glucose by the enzyme electrode; one detects oxygen consumption and the other detects hydrogen peroxide derived from glucose oxidation by the enzyme. Layne et al. [9] first reported an implantable glucose sensor using the oxygen electrode. In their sensor, glucose concentration was measured by the difference in the oxygen tension between the enzyme electrode and the reference oxygen electrode, thus tissue oxygen tension and temperature variations interfered with the output current, which was linear for glucose concentration in the range $0-8.3 \mathrm{mmol} / 1$ only.

A glucose monitoring system based upon the production of hydrogen peroxide from the reaction between glucose and glucose oxidase is incorporated into 
Table 2. The glucoregulatory indices, daily urinary glucose and insulin requirements of three pancreatectomized dogs controlled with the wearable artificial endocrine pancreas

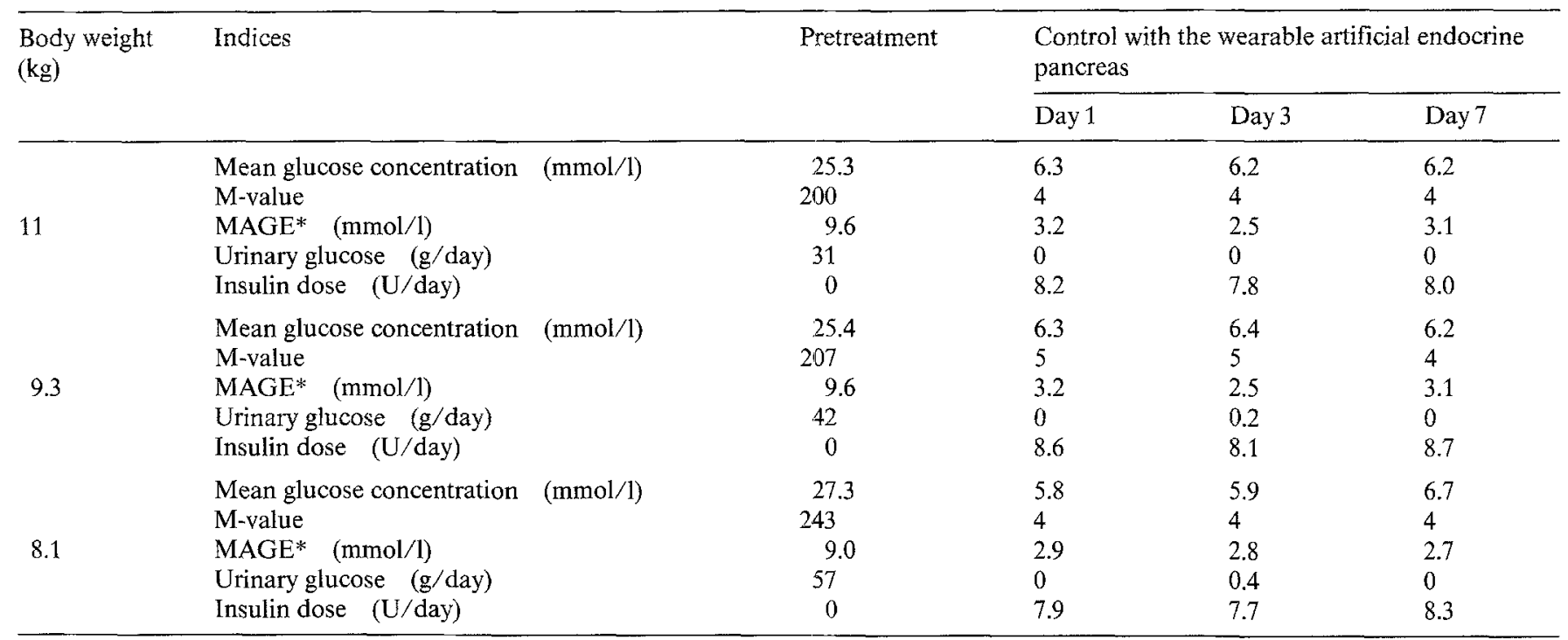

$\mathrm{MAGE}^{*}$; mean amplitude of glycaemic excursions

Mean glucose concentration, M-value [14] and MAGE [15] are calculated from the glucose concentration in SC tissue measured by the sensors. The sensors were replaced by new ones on control day 4 at $06.00 \mathrm{~h}$. In three normal dogs, the mean glucose concentration ranged from 4.8 to $6.8 \mathrm{mmol} / \mathrm{l}$, the M-value was $3-5$, and the MAGE was $2.2-3.8 \mathrm{mmol} / 1$

the bedside-type of artificial endocrine pancreas [4, 5]. In this study, we have succeeded in reducing the size of the glucose sensor to a needle-type. The characteristics of the sensor were examined in vitro in albumin-saline solution. In this solution, the output current generated to $5.5 \mathrm{mmol} / 1$ of glucose was $1.2 \pm 0.4 \mathrm{nA}$, compared with $1.5 \pm 0.7 \mathrm{nA}$ in saline solution. In several experiments with serum in vitro, similar results were obtained as with albumin-saline solution. Noise and baseline drift rarely occurred and the output current in response to glucose concentration showed a linear function in the range $0-27.7 \mathrm{mmol} / 1$ with rapid responses. The temperature coefficient indicated that changes in body temperature would have little effect on the output. Experiments on the dependency of the output on oxygen tension both in vitro and in vivo showed that in the range $25-150 \mathrm{mmHg}$, the current output was not affected significantly. Oxygen tension of SC tissue has been reported to be approximately $30-40 \mathrm{mmHg}$ under physiological conditions $[10,11]$. The present study has corroborated these results, so it appears to be unnecessary to prepare computer algorithms for correcting the sensor output for variations in oxygen tension.

Following intravenous glucose injection, direct measurement of venous glucose by the sensor was consistent with data obtained by the monitoring system. Glucose concentration measured by the sensor inserted into muscle or SC tissue showed a lower and delayed peak after IV glucose pulse load compared with IV monitoring, indicating that there is a time lag for glucose diffusion from blood vessels to extravascular space. However, following oral glucose or meals, current output in intramuscular or SC tissue agreed well with venous blood glucose concentrations. These data indicate that either muscle or SC tissue are satisfactory for possible sensoring sites.

Bessman et al. [13] first reported the treatment of alloxan-diabetic dogs with an implantable closed-loop control system, which operated by battery for 4 days. During the initial 2 days, glycaemia was maintained within the range $5.4-10.7 \mathrm{mmol} / 1$, but afterwards blood glucose showed a remarkably high level.

Short-term treatment of pancreatectomized dogs was conducted to examine the applicability of our system, where the glucose sensor was maintained in SC tissue and insulin was infused intravenously. The insulin infusion algorithms employed were the same as those of the bedside-type of artificial endocrine pancreas [2-4, 12]. The results of continuous monitoring demonstrated that the sensitivity of the sensor was retained at $87 \%$ of the initial activity $72 \mathrm{~h}$ after insertion, but thereafter it reduced considerably. This life expectancy obtained in vivo was similar to that obtained in experiments in vitro using albumin-saline solution. We therefore had to replace the sensors by new ones after $72 \mathrm{~h}$ of use. Loss of biological activity and fixation of albumin and other proteins to the inserted sensor are probably the major causes of its decrease in sensitivity during use in vivo. A more bioadaptable material would be advantageous for covering the surface of the sensor. In the present study, by replacing the sensor with a new one every 4 days, the wearable artificial endocrine pancreas could maintain daily glycaemic variations in diabetic dogs within the range $5-9.5 \mathrm{mmol} / \mathrm{l}$ for 7 days.

In summary, a needle-type glucose sensor has been developed which is disposable and easily exchangeable, 
and which can detect glucose concentrations in various tissues as well as in blood on a real-time basis. A wearable artificial endocrine pancreas, which incorporates a needle-type glucose sensor, has been devised and applied to the glycaemic control of pancreatectomized dogs.

Acknowledgements. This study was supported by a grant from the Ministry of Education, Japan (Grant-in-Aid for Scientific Research No.548354). We are indebted to Dr. S. Kumada (Director, Research Laboratory, Fujisawa Pharmaceuticals, Osaka, Japan) and his staff for their cooperation. The technical assistance of Miss T. Miyatomi is gratefully acknowledged.

\section{References}

1. Albisser AM, Leibel BS, Ewart TG, Davidovac Z, Botz CK, Zingg W, Shipper H, Gander R (1974) Clinical control of diabetes by the artificial pancreas. Diabetes 23: 394-404

2. Kawamori R, Shichiri M, Goriya Y, Yamasaki Y, Shigeta Y, Abe $H$ (1978) Importance of insulin secretion based on the rate of change in blood glucose concentration in glucose tolerance, assessed by the artificial beta cell. Acta Endocrinol (Kbh) 87: 339-351

3. Shichiri M, Kawamori R, Abe H (1979) Normalization of paradoxic secretion of glucagon in diabetics who were controlled by the artificial beta cell. Diabetes $28: 272-275$

4. Kawamori R, Shichiri M, Kikuchi M, Yamasaki Y, Abe H (1980) Perfect normalization of excessive glucagon responses to intravenous arginine in human diabetes mellitus with the artificial beta cell. Diabetes 29: 762-765

5. Clemens AH, Chang PH, Myers RW (1977) The development of Biostator, a glucose controlled insulin infusion system. Horm Metab Res 7 [Suppl]: 22-23

6. Zinman B, Stokes EF, Albisser AM, Hanna HL, Minuk AN, Stein AN, Leibel BS, Marliss EB (1979) The metabolic response to glycemic control by the artificial pancreas in diabetic man. Metabolism 28: 511-517
7. Mirouze J, Selam JL, Pham TC, Mendoza E, Orsetti A (1978) Sustained insulin induced remissions of juvenile diabetes by means of an external artificial pancreas. Diabetologia 14: 223-227

8. Nakagawa S, Nakayama H, Sasaki T, Yoshino K, Yu YY, Shinizaki K, Aoki S, Mashimo K (1973) A simple method for the determination of serum free insulin levels in insulin-treated patients. Diabetes 22: $590-600$

9. Layne EC, Schultz RD, Thomas LJ, Slama G, Sayler DF, Bessman SP (1976) Continuous extracorporeal monitoring of animal blood using the glucose electrode. Diabetes 25:81-89

10. Wakabayashi A, Nakamura Y (1975) Continuous percutaneous monitoring of muscle $\mathrm{pH}$ and oxygen pressure: a new technique for in vivo use. Arch Surg 110: 802-805

11. Van Liew HD (1968) Oxygen and carbon dioxide tensions in tissue and blood of normal and acidotic rats. J Appl Physiol 25: $575-580$

12. Kawamori R, Yamasaki $\mathrm{Y}$, Murata $\mathrm{T}$, Morishima $\mathrm{T}$, Yagi $\mathrm{T}$, Goriya Y, Shichiri M, Abe H (1980) Validation of self-adaptive control algorithm for blood glucose concentration in artificial beta cell. Automedia 3: 183-189

13. Bessman SP, Hellyer JM, Layne EC, Takeda G, Thomas LJ, Sayler D (1977) The total implantation of an artificial B-cell in a dog: progress report. In: JS Bajaj (ed) Excerpta Medica International Congress Series 413: pp 496-501

14. Schlichtkrull J, Munck O, Jersild M (1965) The M-value, an index of blood-sugar control in diabetics. Acta Medica Scand 177: 95-102

15. Service FJ, Molnar GD, Rosevear JW, Ackerman E, Gatewood LC, Taylor WF (1970) Mean amplitude of glycemic excursions, a measure of diabetic instability. Diabetes 19: 644-655

Received: 6 May 1982

and in revised form: 13 October 1982

Dr. M.Shichiri

First Department of Medicine

Osaka University Medical School

1-1-50, Fukushima

Fukushima-Ku, Osaka, 553

Japan 